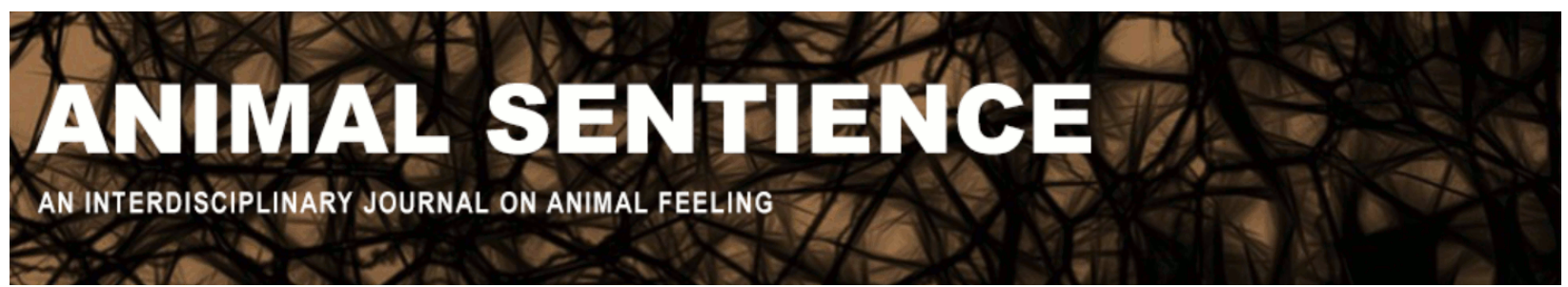

Henry, Bill C. (2016) What does the child protection movement teach us about the role of the mandated reporter of abuse?. Animal Sentience 6(4)

DOI: $10.51291 / 2377-7478.1092$

Date of submission: 2016-02-19

Date of acceptance: 2016-02-26

(c)

This article has appeared in the journal Animal

Sentience, a peer-reviewed journal on animal

cognition and feeling. It has been made open access,

free for all, by WellBeing International and deposited

in the WBI Studies Repository. For more information,

please contact

wbisr-info@wellbeingintl.org.

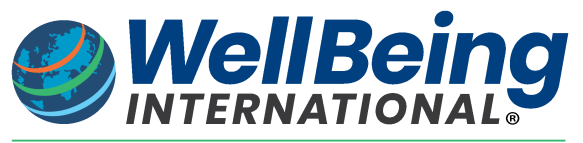

SOLUTIONS FOR PEOPLE, ANIMALS AND ENVIRONMENT 


\title{
What does the child protection movement teach us about the role of the mandated reporter of abuse?
}

Commentary on Lachance on Breaking Silence

\author{
Bill C. Henry \\ Metropolitan State University of Denver
}

\begin{abstract}
Requiring veterinarians to report suspected animal abuse faces many of the same issues, concerns and hurdles once faced by the child protection movement. The history of child protection may hence provide a strategic model for progress in animal protection. Being able to anticipate the hurdles will help prepare us to overcome them.
\end{abstract}

Bill C. Henry henrybi@msudenver.edu, Professor of Psychology, Metropolitan State University of Denver, does research on human-animal interactions, factors influencing attitudes about animals, and factors associated with animal abuse. He currently lives in Denver, Colorado, with his wife, his son, a dog, a cat, two birds, and a gecko. https://msudenver.edu/searchchannel/jsp/directo ryprofile/profile.jsp?uName=henrybi

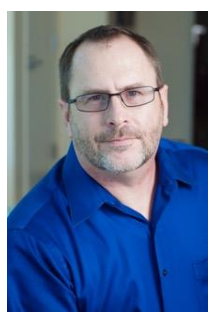

\section{Introduction}

Lachance (2016) offers a passionate call for veterinarians to "break the silence" regarding animal abuse. She argues that this can be accomplished through policies that either free the veterinarian to report suspected cases of animal abuse, or that require the veterinarian to report such cases. Lachance concludes that professional organizations such as the American Veterinary Medical Association (AVMA) or the Canadian Veterinary Medical Association (CVMA) can help establish a culture within which such reporting is part of the ethical standards of the profession. She also refers to governmental/legislative efforts that may contribute to this movement.

In this commentary, I will briefly discuss developments in the field of child protection in the United States, which serve as an historical precedent for developments in the animal protection field. In the United States, it was roughly 50 years ago that State and Federal governments began to formulate child protection laws, and to establish agencies charged with protecting children from abuse. Since the mid-1960s, legislation has developed, becoming more extensive and comprehensive; now, all 50 States as well as the Federal government have legislation requiring intervention in cases of child maltreatment. A central part of this evolution is the role of the "mandated reporter": Individuals who are legally compelled to report cases of suspected child maltreatment. 


\section{The emergence of the mandated reporter in the child protection movement}

In the first half of the $20^{\text {th }}$ century, protecting children from maltreatment was the responsibility of non-governmental organizations, such as the New York Society for the Prevention of Cruelty to Children (NYSPCC). ${ }^{1}$ These organizations were spread across the country, operated independently of one another, and were typically based in urban areas. Very few provided services to children in rural areas (Myers, 2008).

This began to change in 1962 with the publication of a seminal work by C. Henry Kempe and colleagues entitled "The Battered-Child Syndrome." ${ }^{2}$ Kempe et al. described features associated with non-accidental injuries in children, and called upon pediatricians to report cases of suspected maltreatment to police or local child protection organizations. Despite reservations on the part of some physicians (Schmitt \& Kempe, 1975, pp. 32-34), this work spurred State governments to act. By the mid-1960s, all states had laws mandating that medical professionals report suspected child abuse.

(See Myers, 2008; also see https://www.childwelfare.gov/topics/systemwide/laws-policies/.)

While the original mandated reporting laws applied to medical professionals (the rationale being that these individuals would be most qualified to identify maltreatment), the definition of mandated reporter quickly expanded to include other professionals (e.g., clergy, teachers, etc.). Currently, all States require various professional groups (beyond medical professionals) to report suspected abuse, and 18 states require any person suspecting child abuse to report (see http://www.ncsl.org/research/human-services/child-abuse-and-neglect-reportingstatutes.aspx).

\section{The future of the mandated reporter within the animal protection movement}

With this brief history in mind, let us return to the issue of requiring veterinarians to report suspected animal abuse. What might be the consequences of such a development? Based on the historical developments within the field of child protection, we might expect various issues to arise as reporting of suspected animal abuse becomes more commonplace.

Schmitt and Kempe (1975) identified a number of concerns raised by pediatricians when mandated reporting laws were implemented. Many of these concerns will likely be shared by veterinarians faced with reporting suspected abuse. Among others, these concerns included:

\footnotetext{
${ }^{1}$ The similarity between the names "New York Society for the Prevention of Cruelty to Children" and "American Society for the Prevention of Cruelty to Animals" is not accidental. The NYSPCC was created subsequent to, and by many of the same individuals who created the ASPCA. (See http://www.nyspcc.org/about-the-new-york-societyfor-the-prevention-of-cruelty-to-children/history/.) This further illustrates the shared historical roots of the child protection and animal protection movements.

${ }^{2}$ It is worth noting Munro and Thrusfield's (2001) article describing the "Battered-Pet" syndrome. The term "battered-pet" highlights the commonalities between animal abuse and the "battered child syndrome." The fact that Munro and Thrusfield addressed an audience of veterinarians further parallels Kempe's work, which was addressed to pediatricians.
} 
1. Fear of liability: Practitioners may be fearful that they will face lawsuits in the event that the report of suspected abuse is unsubstantiated. Although this fear is unfounded in the case of child abuse (since reporters are protected from retaliatory lawsuits), the practitioner may be unaware of that protection.

2. Fear of damage to practice: The practitioner may fear that the practice will get a "reputation" for reporting abuse.

3. Fear of facing an angry parent (or in this case, pet owner) when it becomes known that the practitioner has reported suspected maltreatment.

4. Desire to avoid bureaucratic entanglements: Reporting suspected abuse may initiate an investigation involving animal control officers as well as the police. If charges are filed against the suspected perpetrator, the reporting veterinarian may be required to testify in court. These activities may appear intimidating and overwhelming to the veterinarian. They may conclude that it is simply easier to turn a blind eye to the suspected abuse.

Beyond these concerns specific to the veterinarian, if mandated reporting becomes widespread, we might expect the definition of mandated reporter to broaden, as occurred in the child protection movement. If veterinarians are required to report, why not boarding facility operators, groomers, or trainers? Indeed, we might envision a scenario in which anyone who suspects animal abuse would be deemed a mandated reporter.

A consideration of the impact of broadening the definition of mandated reporter is premature. However, if indeed "past is prologue" we might be able to anticipate particular outcomes based on historical developments in related fields.

\section{Summary}

The concerns outlined above are not intended as reasons to avoid advocating increased reporting of suspected animal abuse. Rather, they should be seen as obstacles that those of us concerned about animal welfare should expect to face. The movement toward expanded reporting of suspected animal abuse will inevitably face significant political and social resistance, particularly if the reporting is mandatory. Being able to anticipate these hurdles will help prepare us to overcome them.

\section{References}

Kempe, C. H., Silverman, F., Steele, B., Droegemueller, W., \& Silver, H. (1962). The BatteredChild Syndrome. Journal of the American Medical Association, 181, 17-24.

Lachance, M. (2016). Breaking the silence: The veterinarian's duty to report. Animal Sentience 2016.006, 1-16. 
Munro, H., \& Thrusfield, M. (2001). 'Battered Pets': Features that raise suspicion of nonaccidental injury. Journal of Small Animal Practice, 42, 218-226.

Myers, J. (2008). A short history of child protection in America. Family Law Quarterly, 42, 449463.

Schmitt, B., \& Kempe, H. (1975). The pediatrician's role in child abuse and neglect. Current Problems in Pediatrics, 5, 1-47. 